\title{
El Porvenir de la Lengua Española
}

A Bogotá de hace setenta años veía andar por sus calles L a un mozo ensimismado, de aspecto endeble, frente pálida, oscuro el cabello, llenos de espíritu los ojos. Caminaba con la cabeza inclinada, abstraído en sus pensamientos. Su vestido era modesto pero cuidado; llevaba bajo el brazo unos libros. Parecía un místico o un amador, y era ambas cosas a la par.

Don Nicolás Bayona Posada, en el hermoso prefacio que ha escrito para la nueva edición, publicada por él, de las Disquisiciones filológicas de Rufino José Cuervo, nos muestra c6mo el genial gramático, en sus años juveniles, cuando la vida cantaba en su corazón, no se detenía a contemplar las muchachas asomadas a los balcones o a las rejas de las ventanas. No. Cuervo atraviesa la ciudad "sin inquietarse por las beldades que cuchichean con sus prometidos..." "También él -prosigue Bayona Posada-tiene una novia a quien adora: es su lengua"... "Rubia y morena, terrestre y celestial, virgen y madre, ninguna mujer más atractiva, más variada, más bella"... La amada de Cuervo es el habla castellana.

La admira él, la sirve y cultiva, la posee con pasión de enamorado. Pero, al mismo tiempo, la estudia con el más puro criterio científico. "En la elección de mil estudios - confiesa el propio Cuervo- hubo sin duda de obrar el cariño a la lengua materna; hecha la elección, nada puede ni podrá apartarme de la independencia científica"... Y esa fusión del amor al idioma, al verbo, a la palabra, por la que el hombre se hace hombre, y de culto a la ciencia, a la verdad, por 
la que el hombre se hace libre, nos da la clave de la labor fecunda, de la obra magnífica del más grande de los filólogos de la lengua española.

\section{$* * *$}

Antigua es la sentencia que une el amor a los dos grandes principios antagónicos: la vida y la muerte. En el amor, padre de la vida, veía el poeta pesimista al hermano de la muerte. Fratelli a un tempo stesso amore e morte...

Rufino José Cuervo, como enamorado de su lengua materna, admira en ella la vida $\mathrm{y}$, a la vez, tiene el hondo presentimiento de que el habla castellana ha de morir un día. Amante apasionado, piensa en la vida y en la muerte. Nadie há explicado mejor que él que la lengua es una cosa viva, en constante cambio y evolución, en perpetuo movimiento, en renovación incesante. Pero nadie tampoco mejor que Cuervo ha insistido en el penoso pronóstico de que, por efecto de esa misma transformación, el idioma español está llamado a descomponerse y fenecer un día, como acabó el latín, para dar nacimiento a nuevos y diversos lenguajes. La lengua de Cervantes será un día una lengua muerta como la de Horacio.

Contra la terquedad académica que se obstine en fijar un idioma, sostiene Cuervo que el habla, como la vida misma, es una continua evolución. "El lenguaje-nos dice-está en constante movimiento"... "Un idioma no es idéntico ni en el tiempo ni en el espacio: basta abrir un libro, de ahora dos o tres siglos, para persuadirse de que entonces no se hablaba como hoy, y trasladarnos a unas cuantas leguas del lugar donde nacimos, para notar diferencias de pronunciación, vocablos nuevos y frases extrañas"...

Nuestro idioma vive $y$, porque vive, cambia inevitablemente. Cambia el castellano en la propia Castilla; cambia diversamente en las distintas comarcas españolas; cambia en las diferentes naciones de América; cambia en las Islas Filipinas o en el norte de Africa. Varía inquietamente, debe variar, y sus variaciones son normales, vitales, legítimas siempre que respondan a la evolución del espíritu humano y al genio interior del habla. 
Dentro de estas condiciones, las nuevas voces, los nuevos giros del idioma son perfectamente aceptables, lo mismo si se producen en cualquiera de las regiones de América que si nacieran en Avila de los Caballeros o en Madrigal de las Altas Torres. Los "americanismos" gozan de igual derecho de ciudadanía que los "castellanismos" en el ámbito total de la lengua española.

Hasta aquí hemos empleado indistintamente, para designar nuestro idioma, las palabras "español", o "castellano". Recientemente se ha publicado en la Argentina un documentado estudio sobre el uso de los términos "español", "castellano" y "lengua nacional" en los distintos países de América: la elección de uno u otro obedece con frecuencia a razones profundas. El Diccionario de la Academia, que antes se llamó "de la lengua castellana", se llama ahora "de la lengua española". Y el propio Rufino Cuervo, en un pasaje de $E l$ castellano en América, escribe incidentalmente: "El castellano (o digámoslo mejor, el español)"...

Castellano y español ¿no serán, en realidad, dos cosas distintas, dos hablas de matiz diferente? Considerando como "castellano" el lenguaje que se habla y escribe en Castilla, podríamos llamar "español" al idioma, mucho más vasto, común a veinte naciones, con sus múltiples variantes dentro de la misma Península (una de las cuales, y muy ilustre, sería el "castellano") y en las diversas regiones de América.

Todas esas variantes se influyen recíprocamente $\mathrm{y}$ forman, en su conjunto, el actual idioma "español", la amplia lengua internacional, verbo de todo el mundo hispanoamericano, idioma que abarca una gran parte del planeta, $y$ se enriquece, se transforma, evoluciona de cara al porvenir.

\section{$* * *$}

Evoluciona porque vive y porque vive ha de morir, diría melancólicamente Rufino José Cuervo. El amador ve en su amada la vida y la muerte. Alma de asceta, el insigne filólogo medita en que su lengua maternal es perecedera. 
Ese mismo temor apunta ya también en la Gramática de Andrés Bello. "Pero el mayor mal de todos - se lee en el Prólogo-y el que, si no se ataja, va a privarnos de las inapreciables ventajas de un lenguaje común, es la avenida de neologismos de construcción, que inunda y enturbia mucha parte de lo que se escribe en América $y$, alterando la estructura del idioma, tiende a convertirlo en una multitud de dialectos irregulares, licenciosos, bárbaros, embriones de idiomas futuros, que durante una larga elaboración reproducirían en América lo que fué la Europa en el tenebroso período de la corrupción del latín. Chile, el Perú, Buenos Aires, Méjico, hablarían cada uno su lengua, o, por mejor varias lenguas, como sucede en Italia, España y Francia”...

Lo que en la Gramática de Bello aparece como un peligro evitable se presenta en Cuervo con la grandeza de la fatalidad. Precisamente porque, para él, el idioma es un ser vivo, está, cual todo lo que vive, condenado a muerte. La disolución de la lengua española y su desmembración hasta trocarse en nuevas $\mathrm{y}$ diferentes hablas, tendrá que ocurrir necesariamente en el futuro, aunque quizás en un futuro muy lejano. $Y$ no, ciertamente, por culpa de América. "La evolución del lenguaje -explica Cuervo- es natural y forzosa, y la extrañeza que causan a los españoles las peculiaridades de los americanos, es tan poco razonable como la que sintiera un americano por las novedades que cada día se admiten en Castilla".

Lo mismo que con el idioma español ocurrirá con el idioma inglés. Las dos hablas mundiales habrán de perecer en su día, transformándose cada una de ellas en los diferentes países, hasta que de táles divergencias vayan surgiendo las nuevas y distintas lenguas neohispánicas o neobritánicas.

La unidad del habla, en opinión de Cuervo, se irá perdiendo en cada uno de los dos casos, como se perdió la del latín con la decadencia del imperio romano, a medida que decline el influjo espiritual de las viejas metrópolis, y a causa, sobre todo, de "la incomunicación en que viven los Estados americanos"... "Con el aislamiento en que por lamentable necesidad vivimos los pueblos americanos -insiste Cuervo-irán creciendo cada día las diferencias existentes". 
"Incomunicación"... "Aislamiento". . ¿ iNo es cierto que las mismas razones en que Rufino José Cuervo fundamenta su triste profecía al final del siglo XIX, nos servirían ahora para refutarla a la nueva luz del siglo $\mathrm{XX}$ ?

Ya no hay, ya no podrá haber, incomunicación ni aislamiento en el mundo. Entre dos villas de España, en la época en que se formaba nuestro idioma, había más separación, mayor distancia efectiva, que la que hoy existe entre Madrid y La Habana o entre Buenos Aires y la ciudad de Méjico. Atravesar un Continente, cruzar un océano, nos es hoy más fácil de lo que era para Rufino José Cuervo viajar de Bogotá a Medellín. La radiotelefonía nos permite escuchar sin esfuerzo, desde un valle de los Andes, los acentos de la len-. gua española en todas las capitales de América. Con la radio y el avión, con la técnica moderna, los millones de hombres de habla hispana, lo mismo que, por su parte, los de habla inglesa, mantienen un constante coloquio en toda la extensión del planeta. Ya no es un problema la unidad del idioma.

El idioma seguirá su evolución porque ella es su vida; pero su vida no traerá forzosamente su muerte. Los cambios que en el habla se produzcan a orillas del río de La Plata se escucharán por radio inmediatamente en las laderas de los Andes; los de las vertientes andinas resonarán en el Mar de las Antillas; los de América se oirán en España, los de España en América, $y$, por otra parte, la nave aérea llevará en sus alas, con el libro y el periódico, la unidad de la lengua, integrada por la espléndida variedad de sus múltiples matices en todo el mundo.

$$
* * *
$$

En la recogida plaza de San Carlos aparece ahora la estatua de Rufino José Cuervo entre las verdes ramas de los árboles y los rojos tejados de sus viejas casas. Completan el ambiente, en el fondo, las cúpulas de la Catedral. Allí, Cuervo, entre la pluma y el libro, inclinada la noble frente, parece meditar todavía en la vida y la muerte de su amada.

Pero se oye en el aire el zumbido lejano de un avión. Luego, por un balcón abierto, las notas de un aparato de ra- 
dio quiebran el sosiego de la antigua plaza. Vienen de una emisora de la Isla de Cuba, donde una voz de mujer, inconfundiblemente española, canta un tango típicamente argentino... En esta plaza santafereña se juntan de pronto los muelles de La Habana, los jardines andaluces, los arrabales de Buenos Aires...

No, no se disgrega el idioma español, sino que sus diversas modalidades se unen y combinan en cada lugar. Con la técnica del siglo XX está asegurada la universalidad de la lengua. La amada de Cuervo es inmortal.

Inmortal, en cuanto alcanzan las humanas previsiones. Cuando pasen, tras los siglos, los milenios, nadie sabe lo que acaecerá en la Tierra, ni si la humanidad hablará toda ella un solo idioma, o habrá quedado ya, definitivamente, en silencio.

Mas, en lo que cabe prever, no parece probable que se repita en América el bíblico relato de la Torre de Babel. Más bien está ocurriendo el inverso milagro: hombres de todos los pueblos, de todas las razas del Globo, cuyos abuelos hablaron en lejanos climas los más distintos y extraños lenguajes, vienen a unificarse todos, a comprenderse todos, expresándose todos en una misma lengua, nuestro dulce y fuerte idioma común, bajo el claro cielo de América.

LUIS DE ZuLuETA,

Bogotá. 